\title{
$\Delta 40$ p53 controls the switch from pluripotency to differentiation by regulating IGF signaling in ESCs
}

\author{
Erica Ungewitter ${ }^{1,2}$ and Heidi Scrable ${ }^{1,3}$ \\ ${ }^{1}$ Kogod Center on Aging, Mayo Clinic, Rochester, Minnesota 55905, USA; ${ }^{2}$ Graduate Program in Molecular Cell \\ and Developmental Biology, University of Virginia, Charlottesville, Virginia 22908, USA
}

\begin{abstract}
$\Delta 40 \mathrm{p} 53$ is a transactivation-deficient isoform of the tumor suppressor p53. We discovered that $\Delta 40 \mathrm{p} 53$, in addition to being highly expressed in embryonic stem cells (ESCs), is the major p53 isoform during early stages of embryogenesis in the mouse. By altering the dose of $\Delta 40 \mathrm{p} 53$ in ESCs, we identified a critical role for this isoform in maintaining the ESC state. Haploinsufficiency for $\triangle 40$ p53 causes a loss of pluripotency in ESCs and acquisition of a somatic cell cycle, while increased dosage of $\Delta 40 \mathrm{p} 53$ prolongs pluripotency and inhibits progression to a more differentiated state. $\triangle 40 \mathrm{p} 53$ controls the switch from pluripotent ESCs to differentiated somatic cells by controlling the activity of full-length 553 at critical targets such as Nanog and the IGF-1 receptor (IGF-1R). The IGF axis plays a central role in the switch between pluripotency and differentiation in ESCs-and $\Delta 40 \mathrm{p} 53$, by controlling the level of the IGF-1R, acts as a master regulator of this switch. We propose that this is the primary function of $\Delta 40 \mathrm{p} 53$ in cells of the early embryo and stem cells, which are the only normal cells in which this isoform is expressed.
\end{abstract}

[Keywords: $\Delta 40$ p53; embryonic stem cells; pluripotency; IGF]

Supplemental material is available at http://www.genesdev.org.

Received April 27, 2010; revised version accepted September 14, 2010.

p53 prevents cancer growth by activating cell cycle arrest and apoptosis programs in stressed cells, and has been shown recently to inhibit the reprogramming of somatic cells into induced pluripotent stem cells (iPS) using many of the same mechanisms. Depleting p53 levels by either shRNA or homologous recombination significantly increased the reprogramming efficiency of mouse embryonic fibroblasts (MEFs) (Hong et al. 2009; Kawamura et al. 2009; Li et al. 2009; Marion et al. 2009) and even enabled the reprogramming of cell types that normally are unable to generate iPS cells (Utikal et al. 2009). p53 is also an important regulator of pluripotency in normal embryonic stem cells (ESCs) (Lin et al. 2005; Maimets et al. 2008), which are derived from the inner cell mass of blastocyststage embryos and, like iPS cells, are pluripotent and capable of differentiating to form all cell lineages in the body. Although ESCs have high basal levels of p53, they do not undergo normal p53-mediated cell cycle arrest, apoptosis, or senescence following DNA damage (Aladjem et al. 1998; Corbet et al. 1999). Rather, p53 appears to respond to DNA damage signals in ESCs by promoting differentiation (Lin et al. 2005; Maimets et al. 2008). The

${ }^{3}$ Corresponding author.

E-MAIL Scrable.Heidi@mayo.edu; FAX (507) 284-1678.

Article is online at http://www.genesdev.org/cgi/doi/10.1101/gad.1987810. factors controlling this activity in ESCs remain poorly understood.

Emerging evidence that p53 is actually a family of several different protein isoforms that can interact with and modulate the activity of full-length p53 may provide at least a partial explanation. Currently, there are nine known p53 isoforms that are generated by alternate promoter usage (Bourdon et al. 2005), alternative splicing (Ghosh et al. 2004; Bourdon et al. 2005), or alternative translation of a common RNA transcript (Courtois et al. 2002; Lin et al. 2005; for review, see Hollstein and Hainaut 2010). Ectopic overexpression of the largest of these isoforms, known as $\Delta 40$ p53 (also referred to as $\Delta \mathrm{Np} 53$ or p47 in humans and p44 in the mouse), causes p53-dependent progeria and reduced life span in mice (Maier et al. 2004) and impairs the regenerative capacity of adult stem cells (Medrano et al. 2009). In this study, we extended our analysis of the role of $\Delta 40 \mathrm{p} 53$ in stem cells to include ESCs. In contrast to our results in somatic stem cells, ectopic overexpression of $\Delta 40$ p53 in ESCs actually enhances stem cell regenerative capacity by maintaining pluripotency and the abbreviated ESC cell cycle that allows for robust proliferation and growth. Loss of even one copy of $\Delta 40 \mathrm{p} 53$ in ESCs, on the other hand, induces a rapid down-regulation of proliferation, loss of stem cell factors, and acquisition of a somatic cell cycle. We provide 
a mechanism by which the level of $\Delta 40 \mathrm{p} 53$ regulates this switch from pluripotency to differentiation by controlling the expression of Nanog and the IGF-1 receptor (IGF-1R).

\section{Results}

\section{$\Delta 40 p 53$ is highly and specifically expressed in ESCs}

To analyze p53 isoform expression in ESCs, we used Western blot analysis with monoclonal antibodies recognizing distinct epitopes in the $\mathrm{N}$ and $\mathrm{C}$ termini of p53 (Fig. 1A). In addition to full-length p53, PAb248, which recognizes an epitope common to all p53 isoforms, detected a second prominent p53 isoform that migrated with an apparent molecular weight of $\sim 44 \mathrm{kDa}$ (Fig. 1B, top panel). $\Delta 40 \mathrm{p} 53$ is the largest of the short p53 isoforms, with an apparent molecular weight of $44 \mathrm{kDa}$ in the mouse.
However, two C-terminal p53 variants of similar size (42 $\mathrm{kDa} \_\mathrm{p} 53 \beta$ and $\mathrm{p} 53 \gamma$-have been identified in human cells (Bourdon et al. 2005). To discriminate between these three isoforms, we used D0-1, which recognizes an epitope between amino acids 21 and 25 of human p53 (Stephen et al. 1995), and PAb421, which targets a highly conserved epitope in mouse and human p53 at amino acids 371-378 (Yewdell et al. 1986). D0-1 detected a band $\sim 40 \mathrm{kDa}$ in both mouse (Fig. 1B) and human (Supplemental Fig. S1A) ESCs. Based on the apparent molecular weight and the presence of an intact $\mathrm{N}$ terminus, this $40-\mathrm{kDa}$ species could represent either p53 $\beta$ or $\mathrm{p} 53 \gamma$, which in either case is expressed at a relatively low level. The C-terminal antibody $\mathrm{PAb} 421$ reacted very strongly to full-length p53 at $50 \mathrm{kDa}$, and to the $44-\mathrm{kDa}$ isoform in ESC lysates (Fig. 1B). Together with the lack of D0-1 reactivity, the PAb421 recognition pattern strongly suggests that the
A
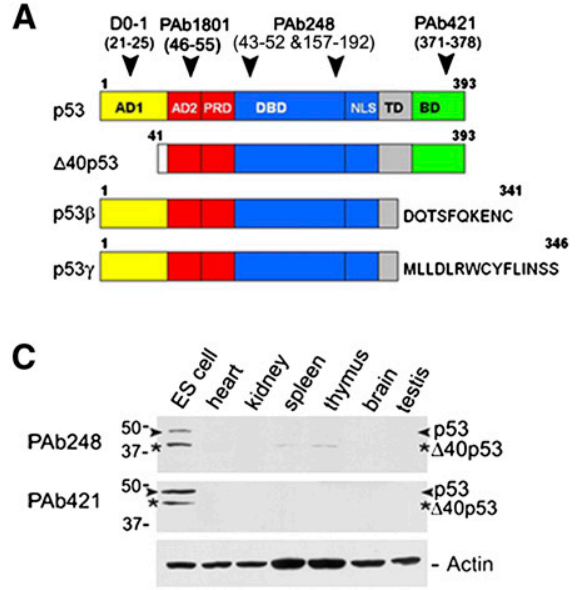

E

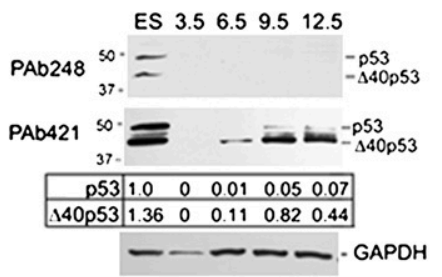

G

PAb248
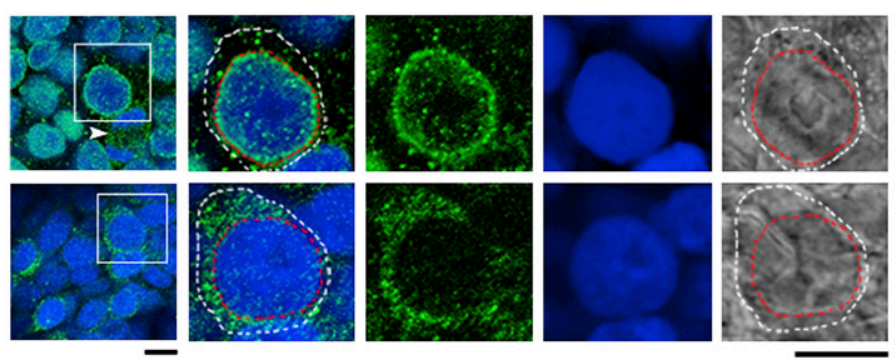

Figure 1. $\Delta 40 \mathrm{p} 53$ is highly expressed in undifferentiated ESCs and early post-implantation embryos. (A) Schematic representation of pertinent p53 protein isoforms. The major functional domains are described fully in the text. (Yellow) Primary transactivation domain (AD1); (red) second transactivation domain (AD2) and proline-rich domain (PRD); (blue) DNA-binding domain (DBD); (gray) tetramerization domain (TD); (green) basic domain (BD). (Arrowheads) Locations of epitopes recognized by the p53 antibodies used in these studies. CM5 is a polyclonal antibody that recognizes multiple unknown epitopes (Lane et al. 1996). (B-E) p53 isoform expression in mouse cells and tissues. All cells and tissues were derived from ICR mice, unless otherwise indicated. (B) Mouse ESCs and MEFs. $(C)$ Adult tissues. $(D)$ EBs differentiated for 5 $\mathrm{d}$ (EB5) or $9 \mathrm{~d}$ (EB9) prior to harvest; the table gives the quantitation of each isoform normalized to actin. (E) Embryos derived from natural matings, with extraembryonic tissues removed prior to analysis; timings are indicated in days post-coitum (dpc); the table gives the quantitation of each isoform normalized to GAPDH. ( $F$ ) Subcellular localization of $\Delta 40 \mathrm{p} 53$ and p53 in ESCs. Nuclear (N) and cytosolic $(\mathrm{C})$ cell fractions isolated from normal $129 / \mathrm{SvJ}$ and ICR or p44Tg ESCs and analyzed by Western blotting. Ratios of normalized values of $\Delta 40 \mathrm{p} 53$ to full-length p53 are indicated below each lane. $(G)$ Immunolocalization of p53 in ESCs. Immunofluorescent staining for PAb248 (top, green) and PAb421 (bottom, green) was performed on wild-type 129/SvJ ESCs, and nuclei were counterstained with DRAQ5. Images are $1 \mu \mathrm{M}$ confocal sections collected using a Zeiss Std510 microscope; red dashed lines were traced around the nuclear envelope boundary, and white dashed lines were traced around the outer cell membrane. Bar, $10 \mu \mathrm{m}$. See also Supplemental Figure S1. 
$44-\mathrm{kDa}$ p53 species is $\Delta 40 \mathrm{p} 53$. To confirm the identity of this smaller isoform, we performed mass spectrometry following immunoprecipitation with PAb248 and isolation of the band migrating at $44 \mathrm{kDa}$ on SDS-PAGE. The p53related peptides spanned the proline-rich domain, DNAbinding domain, and basic domain (Fig. 1A), but did not include the primary transactivation domain in the $\mathrm{N}$ terminus of p53, consistent with $\Delta 40 \mathrm{p} 53$ but no other isoform (Supplemental Fig. S1C-E). We conclude that full-length p53 and $\Delta 40$ p53 are highly expressed in mouse ESCs, and that $\mathrm{p} 53 \beta / \mathrm{p} 53 \gamma$ is also present, although at a much lower level. Human ESCs show a similar pattern of p53 isoform expression (Supplemental Fig. S1A).

The relatively high level of both p53 and $\Delta 40$ p53 in ESCs is in stark contrast to the levels in normal adult tissues, where there is little or no constitutive expression of either isoform (Fig. 1C). To determine if this might reflect loss of $\Delta 40 \mathrm{p} 53$ with progression to a more differentiated state, we compared p53 isoform expression in ESCs and embryoid bodies (EBs). As shown in Figure 1D, we found that the levels of $\mathrm{p} 53$ and $\Delta 40 \mathrm{p} 53$ protein declined in EBs relative to undifferentiated ESCs, and that the level of $\Delta 40$ p53 continued to decrease with longer periods of EB culture coincident and in parallel with the loss of stem cell markers such as Oct4 (Pou5f1). This decrease in $\Delta 40 \mathrm{p} 53$ protein during EB differentiation was not the result of decreased mRNA expression (Supplemental Fig. S2A). These data demonstrate that $\Delta 40 \mathrm{p} 53$ is expressed most prominently in ESCs, and that $\Delta 40$ p53 expression declines during ESC differentiation by a mechanism involving posttranscriptional rather than transcriptional alterations in gene expression.

To determine if the high level of $\Delta 40$ p53 in ESCs is an accurate reflection of $\Delta 40 \mathrm{p} 53$ expression during early embryogenesis, we harvested embryos from naturally mated females, isolated protein, and performed Western blotting using the p53 antibodies PAb248 and PAb421. We detected appreciable levels of $\Delta 40 \mathrm{p} 53$ beginning at 6.5 $\mathrm{d}$ post-coitum (dpc) in embryonic tissues using antibody PAb421 (Fig. 1E). Full-length p53, on the other hand, did not begin to be expressed until $9.5 \mathrm{dpc}$. We did not find p53 or $\Delta 40$ p53 in any of these embryos using PAb248, which we attribute to phosphorylation-dependent changes in epitope recognition (Supplemental Fig. S1F). In summary, our findings reveal that $\Delta 40 \mathrm{p} 53$ is an embryonic isoform of p53 whose expression is highest in pluripotent stem and progenitor cells prior to the onset of terminal differentiation. In mouse embryogenesis, $\Delta 40 \mathrm{p} 53$ can first be detected in early post-implantation embryos, several days before the appearance of full-length p53.

$\Delta 40 p 53$ is in both the nucleus and cytoplasm of ESCs, but is differentially phosphorylated

To determine if $\Delta 40 \mathrm{p} 53$ might regulate the activity of full-length p53 in ESCs, we first had to determine if the two isoforms colocalized within the cell. To do this, we fractionated ESCs into nuclear and cytoplasmic compartments and analyzed isoform expression by Western blot using PAb248 and PAb421. Both antibodies detected full- length p53 in both the nucleus and cytosol (Fig. 1F). Both antibodies also detected $\Delta 40 \mathrm{p} 53$ in the nucleus, but only PAb421 detected this isoform in the cytoplasm (Fig. 1F). As epitope recognition by PAb421 and PAb248 is oppositely affected by phosphorylation, we could also determine the subcellular localization of phosphorylated and unphosphorylated forms of p53 and $\Delta 40$ p53 with these data. Phosphorylation blocks the epitope recognized by PAb421 (Warnock et al. 2005); therefore, unphosphorylated $\Delta 40 \mathrm{p} 53$ predominates in the cytoplasm. On the other hand, phosphorylation is necessary for recognition by PAb248 (Supplemental Fig. S1F), indicating that phosphorylated $\Delta 40 \mathrm{p} 53$ predominates in the nucleus. This in contrasts to p53, which exists in both phosphorylated and unphosphorylated forms in both the nucleus and cytoplasm. We found a similar pattern of reactivity in human ESCs, except that phosphorylation of nuclear $\Delta 40 \mathrm{p} 53$ was reduced relative to mouse ESCs (Supplemental Fig. S1B).

Immunocytochemistry and confocal imaging confirmed the differential localization of phosphorylated and unphosphorylated forms of p53 and $\Delta 40 \mathrm{p} 53$ (Fig. 1G). The nuclear fraction of phosphorylated p53 and $\Delta 40 \mathrm{p} 53$ detected by PAb248 localizes to the perimeter of the nucleus, apparently just inside the nuclear envelope (Fig. 1G, top). In mitotic cells in which the chromosomes are condensed and the nuclear envelope is disassembled (Fig. 1G, arrowheads), this pattern is lost and staining becomes uniformly distributed. PAb421 staining, on the other hand, was predominantly cytosolic (Fig. 1G, bottom). Thus, while the distribution of phosphorylated and unphosphorylated forms of p53 appears to be similar in the nucleus and cytoplasm of ESCs, $\Delta 40 \mathrm{p} 53$ is distributed unevenly, with phosphorylated $\Delta 40 \mathrm{p} 53$ in the nucleus and unphosphorylated $\Delta 40 \mathrm{p} 53$ in the cytoplasm.

\section{$\Delta 40$ p53 promotes ESC survival}

Subcellular fractionation and immunocytological data demonstrated that full-length p53 and $\Delta 40$ p53 are localized to the same areas in ESCs. To explore the hypothesis that complexes between these two isoforms might regulate p53 function in ESCs, we used genetic means to increase or decrease the level of $\Delta 40 \mathrm{p} 53$ in ESCs. To generate ESCs with an increased dose of $\Delta 40 \mathrm{p} 53$, we used a line of transgenic mice that have, in addition to their two normal p53 alleles, an ectopic copy of p53 in which the start site for full-length p53 is missing (p44Tg mice). Compared with normal ESCs, ESCs derived from p44Tg embryos express slightly higher levels of $\Delta 40$ p53 (Fig. 2A).

This increase in $\Delta 40 \mathrm{p} 53$ expression appears to facilitate the generation of ESC lines from ICR (CD-1) blastocysts, which are notoriously difficult to derive compared with other laboratory strains (Suzuki et al. 1999). Using standard culture techniques (Nagy et al. 2003), we were able to derive two ESC lines from five p44Tg blastocysts (for a cloning efficiency of $40 \%$ ), but no lines from 38 nontransgenic blastocysts (Fig. 2B). To begin to understand this ESC cloning advantage, we compared the growth and death rates of p44Tg ESCs with normal ICR ESCs provided by Dr. Robin Wesselschmidt (Primogenix, Inc., Los 
A

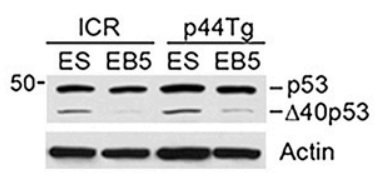

B

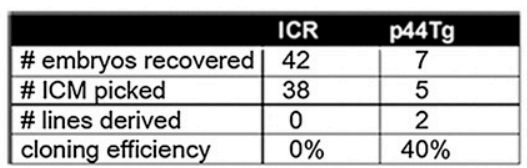

C

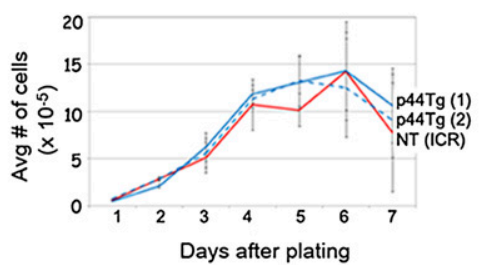

E

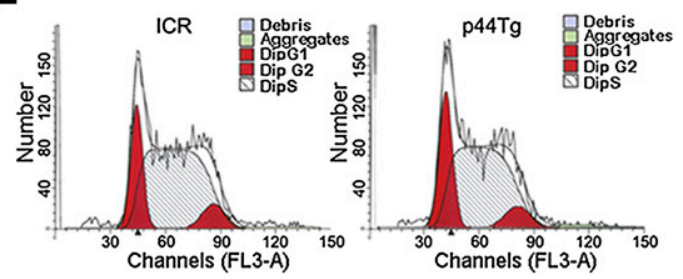

D

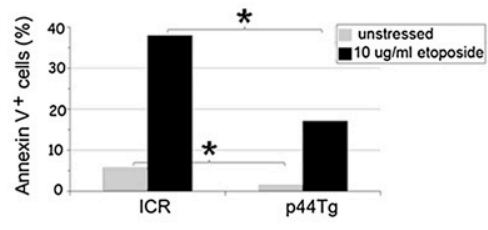

$\mathbf{F}$

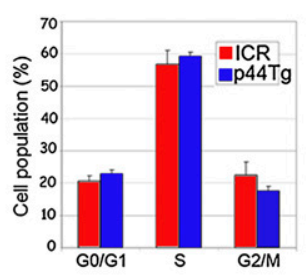

Figure 2. $\quad \Delta 40 \mathrm{p} 53$ promotes ESC survival. $(A)$ p53 isoform expression in normal and p44Tg ESCs and EBs. Western blot reacted with PAb248 for p53 isoform expression and actin for total protein. (B) Derivation of ESCs from wild-type (ICR) and p44Tg embryos. The inner cell mass (ICM) was isolated from each embryo that survived to the expanded blastocyst stage. Cloning efficiency is calculated as the number of ESC lines established from all inner cell masses picked. (C) Growth curves of p44Tg (blue) and nontransgenic (red) ESCs. Data points represent the average \pm SD of triplicate samples counted daily. Three to five replica assays were performed per cell group. Two independent clones of p44Tg ESCs were analyzed, and are designated by the solid and dashed lines. $(D)$ Apoptosis in stressed and unstressed ESCs. Apoptosis is expressed as the percentage of Annexin V-positive cells in FACS-sorted populations. $\left({ }^{\star}\right) P<0.005$ (Pearson's $\chi^{2}$ test). (Gray bars) Untreated cells; (black bars) cells treated with $10 \mathrm{mg} / \mathrm{mL}$ etoposide. $(E, F)$ Cell cycle profiles of ICR and p44Tg ESCs. (E) DNA content in ICR (left) and p44Tg (right)

ESCs analyzed by FACS and MODFIT. (F) Cell cycle distribution in ICR (red bars) and p44Tg (blue bars) ESCs. Values represent mean \pm SEM of six to 10 samples per genotype.

Angeles, CA). Although the growth rates of p44Tg ESCs (Fig. 2C, blue lines) and ICR ESCs (Fig. 2C, red line) were indistinguishable from one another, cell death in cultures of p44Tg ESCs was significantly less than in cultures of normal ESCs both under basal conditions (Fig. 2D, gray bars) and after genotoxic stress (Fig. 2D, black bars). In contrast to these differences in cell death rates, FACS analysis (Fig. 2E,F) indicated that p44Tg ESCs have the same cell cycle distribution as normal ESCs. We conclude that the increase in cell survival during p44Tg embryo culture and ESC isolation is due primarily to reduced cell death, probably by apoptosis, and not impaired growth. This suggests that $\Delta 40 \mathrm{p} 53$ regulates the normal ESC response to stress mediated by $\mathrm{p} 53$.

\section{Decreased $440 p 53$ leads to cell cycle arrest and a spontaneous loss of ESC pluripotency}

To generate ESCs with reduced $\Delta 40 \mathrm{p} 53$ expression, we used site-directed PCR mutagenesis to generate a mutation that eliminates the start codon for $\Delta 40 \mathrm{p} 53$ in exon 4 (M41A) (Fig. 3A). We inserted a floxed neomycin selection cassette with a poly-A-STOP (pA-STOP) sequence into intron 4 of the targeting vector to prevent indeterminate expression in recombinant ESCs. Prior to Cre recombinasemediated recombination, transcription of the $p 53^{4 \text { p44STOP }}$ allele (Fig. 3B) terminates at the pA-STOP sequence and produces a nonfunctional fragment of p53 containing only exons $1-4$, making $\mathrm{p} 53^{+/ \Delta \mathrm{p} 44 \mathrm{STOP}}$ ESCs functionally $\mathrm{p} 53^{+/-}$. We identified nine correctly targeted ESC clones by Southern blot (Fig. 3C) and DNA sequence analysis. Following electroporation of Cre recombinase, we used replica plating and neomycin selection to identify G418-sensitive $\mathrm{p} 53^{+/ \Delta \mathrm{p} 44}$ colonies, then confirmed recombination of the $p 53^{\Delta p 44}$ allele using PCR (Fig. 3D). As expected, p53 $3^{+/ \Delta \mathrm{p} 44}$ ESCs expressed normal levels of full-length p53, but only half the amount of $\Delta 40 \mathrm{p} 53$ found in wild-type ESCs (Fig. 3E).

Compared with the parental p53 $3^{+/ \Delta \mathrm{p} 44 \mathrm{STOP}}$ ESCs, $\mathrm{p} 53^{+/ \Delta \mathrm{p} 44}$ ESCs exhibited a rapid and profound growth arrest. As shown in Figure 3F, the number of p53 $3^{+/ \Delta \mathrm{p} 44}$ ESCs (blue lines) increased at a much slower rate than that of wildtype 129/SvJ ESCs (red lines) or p53 $3^{+/ \Delta \text { p44STOP }}$ ESCs (black lines). This difference was not due to increased cell death (Fig. 3G). Rather, we found by FACS analysis that the majority of $\mathrm{p} 53^{+/ \Delta \mathrm{p} 44}$ ESCs exhibited a highly unusual cell cycle distribution, with most cells in the G0/G1 fraction compared with normal ESCs, which were found primarily in the $\mathrm{S}$ fraction (Fig. $3 \mathrm{H}$ ). This cell cycle profile of $\mathrm{p} 53^{+/ \Delta \mathrm{p} 44}$ ESCs is indistinguishable from that of somatic cells, typified by that of MEFs (Fig. 3I, cf. green and blue bars). These results demonstrate that differences in the growth characteristics of $\mathrm{p} 53^{+/ \Delta \mathrm{p} 44}$ ESCs arise from alterations to the cell cycle such that the $\mathrm{p} 53^{+/ \Delta \mathrm{p} 44}$ cell cycle resembles that of a typical somatic cell rather than that of an ESC.

To determine if haploinsufficiency for $\Delta 40 \mathrm{p} 53 \mathrm{might}$ have caused cells to lose stem cell characteristics, we assessed the expression of the ESC-specific surface marker SSEA-1 using flow cytometry. We found that only $5 \%$ of p $53^{+/ \Delta \mathrm{p} 44}$ cells exhibited SSEA-1 reactivity compared with $93 \%$ of normal ESCs (Fig. 4A). The parental p53 $3^{+/ \Delta \mathrm{p} 44 \mathrm{STOP}}$ ESCs exhibited SSEA-1 expression levels similar to that of normal ESCs, thereby demonstrating that the loss of SSEA-1 in $\mathrm{p}^{+/ \Delta \mathrm{p} 44}$ cells is the specific result of the reduction in $\Delta 40 \mathrm{p} 53$ rather than a side effect of the gene targeting. Using Western blot analysis, we confirmed the loss of the stem cell/pluripotency factors Nanog and Oct4 
A

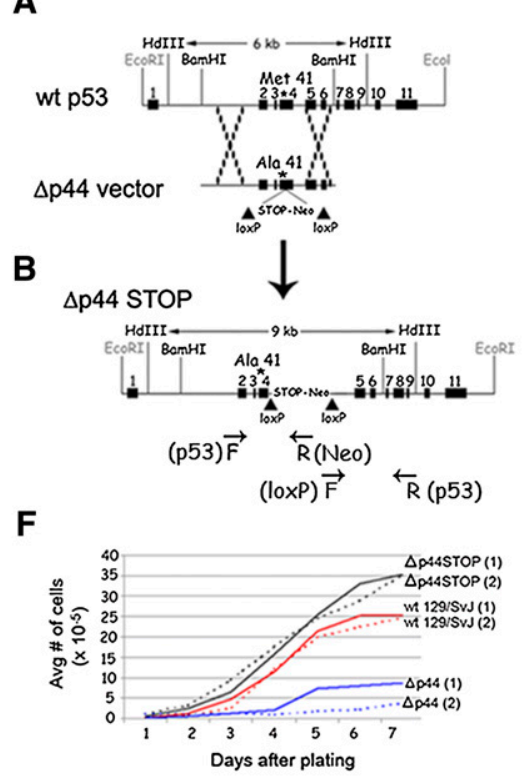

H

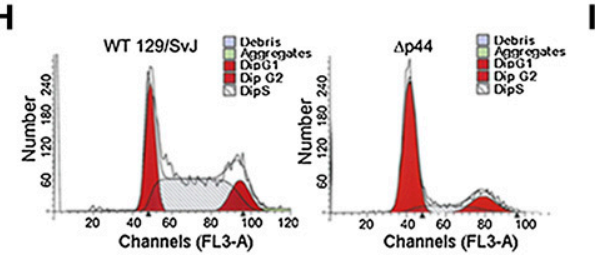

C

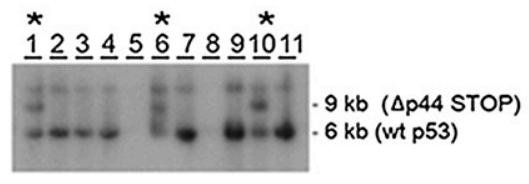

D

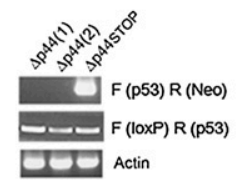

E

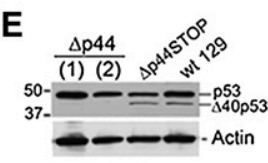

G
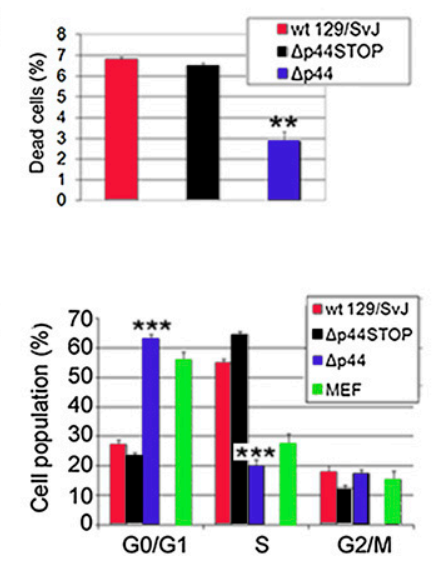

Figure 3. $\Delta 40 \mathrm{p} 53$ is required for ESC proliferation. $(A, B)$ Gene targeting strategy used to generate ESCs with reduced levels of $\Delta 40 \mathrm{p} 53$. (A) Homologous recombination between the normal p53 allele (top) and the $\Delta \mathrm{p} 44$ targeting vector (bottom) results in replacement of Met41 with Ala41 and insertion of a floxed neomycin selection cassette with a pA-STOP sequence. $(B)$ Resultant $\triangle p 44 S T O P$ allele. Primers used to detect the mutant allele following Cre recombinase-mediated deletion of the Neo-STOP cassette are illustrated below. $(C)$ Identification of correctly targeted clones by Southern blot analysis. In HindIII-digested DNA, the normal allele is $6 \mathrm{~kb}$ and the recombinant allele is $9 \mathrm{~kb}$ due to the insertion of the NeoSTOP cassette. $\left({ }^{\star}\right)$ Correctly targeted heterozygous $\mathrm{p} 53^{+/ \Delta \mathrm{p} 44 \mathrm{STOP}}$ ESC clones. $(D)$ Identification of $\mathrm{p} 53^{+/ \Delta \mathrm{p} 44}$ ESCs by PCR analysis. Ethidium bromide (EtBr)-stained gel of PCR products before $(\Delta \mathrm{p} 44 \mathrm{STOP})$ and after $[\Delta \mathrm{p} 44(1)$ and $\Delta \mathrm{p} 44(2)]$ transduction of ESCs with Cre recombinase. $\mathrm{F}(\mathrm{p} 53)$; $\mathrm{R}(\mathrm{Neo})$ (top) and $\mathrm{F}(\operatorname{lox} \mathrm{P}) ; \mathrm{R}(\mathrm{p} 53)$ (middle) primer pairs are shown in B. (Bottom) Actin and control primers. $(E)$ p53 isoform expression in wildtype $129 /$ SvJ, $\Delta$ p44STOP, and $\Delta$ p44 ESCs. Western blot reacted with PAb421 for p53 isoform expression and actin for total protein. $(F)$ Growth curves of wild-type (129/ SvJ) (red), heterozygous p $53^{+/ \Delta 444}$ (blue), and $\mathrm{p} 53^{+/ \Delta \mathrm{p} 44 \mathrm{STOP}}$ (black) ESCs. Data points represent the mean of triplicate samples counted daily. Two different clones were analyzed for each genotype, designated by the solid versus dashed lines. $(G)$ Cell viability of p53 ${ }^{+/ \Delta p 44}$ ESCs (blue) relative to wild-type $(129 / \mathrm{SvJ})$ (red) and p53 ${ }^{+/ \Delta \mathrm{p} 44 \mathrm{STOP}}$ (black). Values represent the mean percentage of dead cells \pm SEM. Dead cells were determined by LIVE/DEAD assay (Invitrogen) and total cells were determined by counting DAPI-positive nuclei. $\left(^{\star \star}\right) P<0.005$ (Pearson's $\chi^{2}$ test). $(H, I)$ Cell cycle profiles of normal and mutant ESCs. $(H)$ DNA content in wild-type $129 /$ SvJ (left) and p53 ${ }^{+/ \Delta \mathrm{p}^{4}}$ (right) ESCs analyzed by FACS and MODFIT. (I) Cell cycle distribution in $129 / \mathrm{Sv}$ (red), p53 $3^{+/ \Delta \mathrm{p} 44 \mathrm{STOP}}$ (black), and p53 ${ }^{+/ \Delta 444}$ (blue) ESCs or MEFs (green). Values represent mean \pm SEM of six to 10 samples per genotype. $\left(^{\star \star \star}\right) P<0.001$ (two-tailed Student's $t$-test).

in $553^{+/ \Delta p 44}$ cells (Fig. $4 \mathrm{~B}$ ). Furthermore, p53 $3^{+/ \Delta \mathrm{p} 44}$ ESCs formed colonies in which only a few cells exhibited low alkaline phosphatase (AP) expression, whereas normal ESCs exhibited the typical ESC morphology of large, well-defined colonies and high AP activity (Fig. 4C). Together, these data show that loss of only one dose of $\Delta 40 \mathrm{p} 53$ causes loss of pluripotency in ESCs. p53 $3^{+/ \Delta \mathrm{p} 44}$ ESCs no longer display the unique ESC characteristics of a rapid cell cycle with short gap phases, elevated AP activity, and high SSEA-1, Nanog, and Oct4 expression, suggesting that a reduction in $\Delta 40 \mathrm{p} 53$ favors differentiation over pluripotency.

We next evaluated the expression of lineage-specific

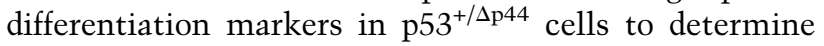
if these cells had entered a known differentiation pathway. We found no differences in the levels of the early mesoderm marker Brachury or the early neural marker Nestin (data not shown), but discovered that the endodermal marker GATA-4 had an altered expression pattern in $\mathrm{p} 53^{+/ \Delta \mathrm{p} 44}$ compared with normal ESCs. GATA-4 is a 50$\mathrm{kDa}$ transcription factor that requires post-translational modification by sumoylation to activate cardiogenic genes in pluripotent cells (Wang et al. 2004). Stepwise addition of sumo moieties on GATA-4 generates a ladder of multisumoylated GATA-4 species that migrate between 60 and $75 \mathrm{kDa}$. As shown in Figure 4D, $\mathrm{p} 53^{+/ \Delta \mathrm{p} 44}$ cells had reduced levels of the unmodified GATA-4 protein at $50 \mathrm{kDa}$ and increased expression of multisumoylated GATA-4 species at $60-75 \mathrm{kDa}$ compared with normal ESCs. This suggests that $\mathrm{p} 53^{+/ \Delta \mathrm{p} 44}$ cells have undergone precocious differentiation along an endodermal pathway.

\section{Increased 440p53 inhibits ESC differentiation}

Based on the spontaneous loss of pluripotency in $\mathrm{p} 53^{+/ \Delta \mathrm{p} 44}$ cells, we predicted that an additional dose of $\Delta 40 \mathrm{p} 53$ might have the opposite effect of promoting ESC pluripotency and impeding differentiation. To test this hypothesis, we used a modified EB culture system to compare the differentiation potential of $\mathrm{p} 44 \mathrm{Tg}$ and normal (ICR) ESCs. We found that, after $4 \mathrm{~d}$ in culture, EBs derived from $\mathrm{p} 44 \mathrm{Tg}$ ESCs had significantly larger diameters (Fig. 5A) and higher survival rates (Fig. 5B) than EBs derived from ICR ESCs. Next, we used a monolayer differentiation protocol to investigate the effect of $\Delta 40 \mathrm{p} 53$ on cell proliferation during ESC differentiation. As shown in Figure 5C, p44Tg cells 
A
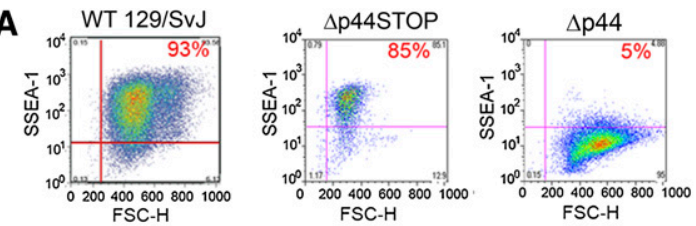

B

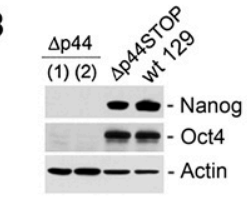

D

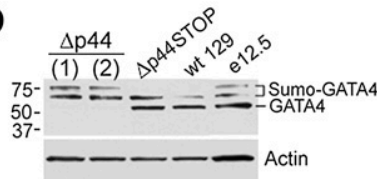

C

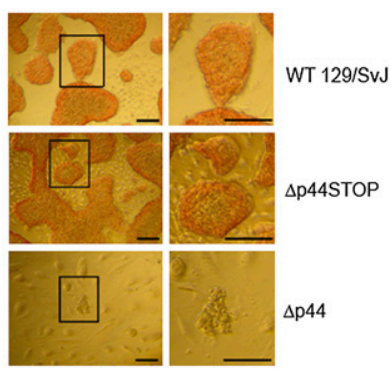

Figure 4. Reduced $\Delta 40 \mathrm{p} 53$ expression leads to spontaneous loss of ESC pluripotency. (A) Reduced SSEA-1 expression in ESCs haplosufficient for $\Delta 40 \mathrm{p} 53$. FloJo FACS analysis of SSEA-1 staining ( $Y$-axis) plotted against forward scatter (FSC) ( $X$-axis) in wild-type (129/SvJ; left), p53 ${ }^{+/ \Delta \mathrm{p} 44 \mathrm{STOP}}(\Delta \mathrm{p} 44 \mathrm{STOP} ;$ middle), and $\mathrm{p} 53^{+/ \Delta \mathrm{p} 44}(\Delta \mathrm{p} 44$; right $)$ ESCs. (B) Loss of stem cell markers in ESCs with reduced $\Delta 40 \mathrm{p} 53$. Western blot analysis of Nanog and Oct4 expression in $\mathrm{p} 53^{+/ \Delta \mathrm{p} 44}(\Delta \mathrm{p} 44)$ cells relative to wildtype $(129 / \mathrm{SvJ})$ or $\mathrm{p} 53^{+/ \Delta \mathrm{p} 44 \mathrm{STOP}}(\Delta \mathrm{p} 44$ STOP) ESCs. $\Delta \mathrm{p} 44(1)$ and $\Delta \mathrm{p} 44(2)$ represent two unique $\mathrm{p} 53^{+/ \Delta \mathrm{p} 44}$ clones. (C) Decreased AP activity in ESCs with reduced $\Delta 40 \mathrm{p} 53$. Histochemical detection of $\mathrm{AP}$ activity in $\mathrm{p} 53^{+/ \Delta \mathrm{p} 44}(\Delta \mathrm{p} 44 ;$ bottom $), \mathrm{p} 53^{+/ \Delta \mathrm{p} 44 \mathrm{STOP}}$ $(\Delta \mathrm{p} 44 \mathrm{STOP}$; middle $)$, and wild-type $(129 / \mathrm{SvJ}$; top) ESC colonies. Images are phase-contrast photomicrographs of cells incubated with a substrate that is converted to a red reaction product in the presence of AP. Bar, $100 \mu \mathrm{m}$. (D) Altered GATA4 expression in ESCs with reduced $\Delta 40 \mathrm{p} 53$. Western blot

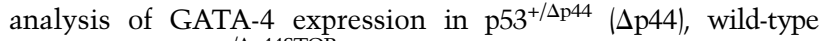
$(129 / \mathrm{SvJ})$, or $\mathrm{p} 53^{+/ \Delta \mathrm{p} 44 \mathrm{STOP}}(\Delta \mathrm{p} 44 \mathrm{STOP})$ ESCs and embryonic day 12.5 (E12.5) embryonic tissues. High-molecular-weight bands correspond to sumoylated forms of GATA-4, and are described fully in the text.

(blue line) divided more rapidly than ICR controls (red line) at every density tested, indicating that they failed to reduce their proliferation rates in response to differentiation signals. We also monitored the morphology of p44Tg and ICR cells during monolayer differentiation culture, and performed immunocytochemical staining to gauge the differentiation response of each group. We noticed differences between p44Tg and ICR cultures as early as the second day of differentiation (data not shown). ICR ESCs attached to the tissue culture dish as a monolayer and adapted a large, flattened morphology after only $7 \mathrm{~d}$, while p44Tg ESCs continued to grow as large, three-dimensional colonies (Fig. 5D). We also observed that the ESC marker SSEA-1 was still highly expressed in p44Tg cells after $14 \mathrm{~d}$ of differentiating treatment, whereas SSEA-1 was lost from ICR cultures within just $3 \mathrm{~d}$ of the monolayer differentiation (Fig. 5D, bottom panels). The stem cell factors Oct 4 and Nanog also failed to decrease sufficiently in p44Tg EBs (Fig. 5E). Together, these data confirm that the dose of $\Delta 40 \mathrm{p} 53$ switches ESCs between pluripotency and differentiation.

\section{0p53 modulates p53-mediated transcription of pluripotency genes}

To begin to understand how $\Delta 40 \mathrm{p} 53$ might effect this switch, we analyzed both the total level of p53 isoform expression and the level of p53 transcriptional activity in normal and p44Tg ESCs and EBs derived from them. As indicated previously (Fig. 2A), differentiation into EBs resulted in a dramatic loss of $\Delta 40 \mathrm{p} 53$ relative to fulllength p53, with p44Tg EBs retaining slightly higher levels of $\Delta 40 \mathrm{p} 53$ compared with normal EBs. This resulted in dramatic differences in complex formation and localization, as shown in Figure 6A. In ESCs of both genotypes, higher-order oligomers (dimers and tetramers) localized to the cytoplasm. As cells differentiated, there was a general shift of p53 oligomer complexes to the nucleus in both normal and p44Tg cells; however, p44Tg EBs retained higher cytosolic levels of p53 dimers and
A

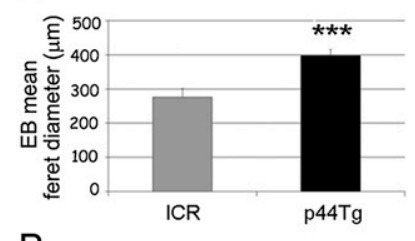

B

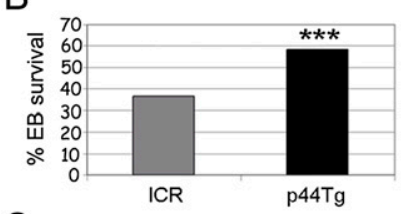

C

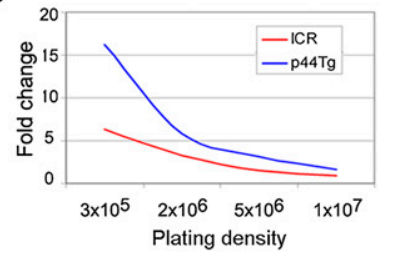

D

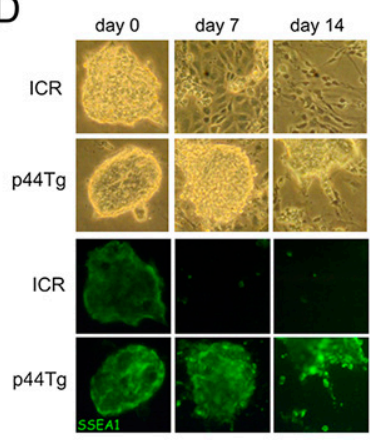

$E$

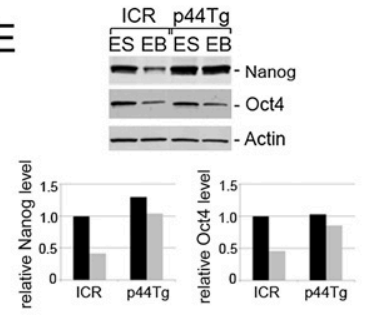

Figure 5. Increased $\Delta 40 \mathrm{p} 53$ inhibits ESC differentiation. $(A)$ Larger size of EBs with increased $\Delta 40 \mathrm{p} 53$. Quantitative analysis of mean diameters of ICR and p44Tg EBs \pm SEM after $4 \mathrm{~d}$ of EB culture. $\left(^{\star \star \star}\right) P<0.001$ (two-tailed Student's $t$-test). $(B)$ Improved survival of EBs with increased $\Delta 40$ p53 EB viability was calculated based on the percentage of all wells plated containing at least one EB after $4 \mathrm{~d}$ of culture. Mean survival rates \pm SEM are displayed. $\left(^{\star \star \star}\right) P<0.001$ (two-tailed Student's $t$-test). $(C-E)$ Impaired response to differentiation conditions in cells with increased $\Delta 40 \mathrm{p} 53 .(C)$ Proliferation of cells during monolayer differentiation. Data are displayed as the fold change in cell number based on the number of ESCs plated on day 1. (Blue) p44Tg; (red) ICR. $(D)$ Phenotype of cells during monolayer differentiation. Photomicrographs of ICR and p44Tg ESCs at days 0,7 , and 14 of monolayer differentiation. (Top panels) Phase contrast. (Bottom panels) Immunofluorescence with an antibody against SSEA-1. Original magnification, 40×. (E, top panel) Western blot analysis of Nanog and Oct4 expression in ICR and p44Tg ESCs and day 5 EBs. Protein quantitation in ESCs (black bars) and EBs (gray bars), normalized to actin, is displayed below. The Oct 4 antibody detects a doublet at $44 / 42 \mathrm{kDa}$; both bands of the doublet were measured for the quantitation. 


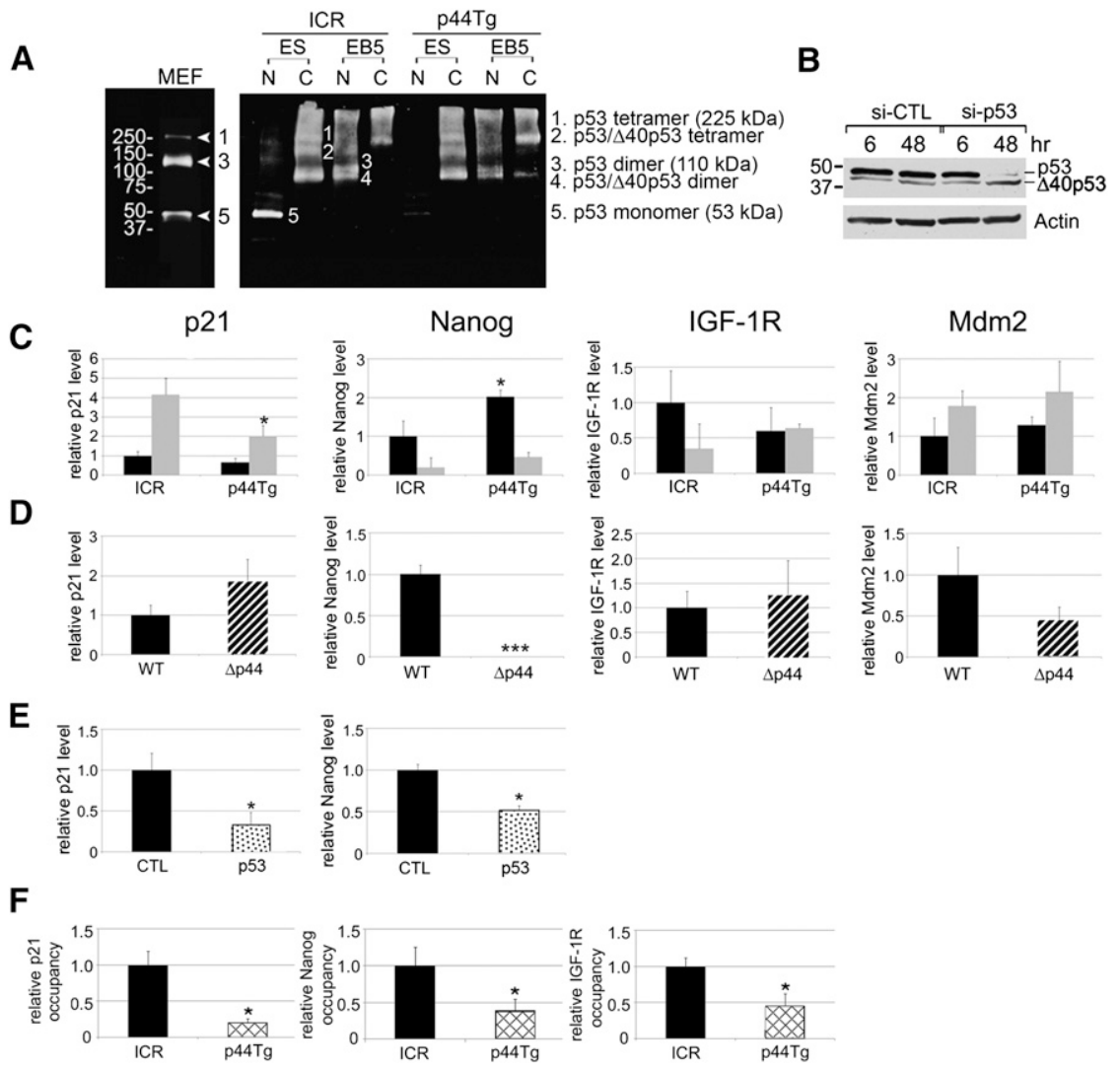

Figure 6. $\Delta 40 \mathrm{p} 53$ modulates p53-mediated transcription of pluripotency genes. (A) Oligomers of p53 and $\Delta 40 \mathrm{p} 53$ in normal and p44Tg ESCs and EBs. Representative Western blot of gluteraldehyde-treated nuclear $(\mathrm{N})$ and cytosolic $(\mathrm{C})$ fractions of ICR and p44Tg ESCs or day 5 EBs (EB5). p53 detection by PAb248. At least four samples from each genotype were tested, with consistent results. Bands corresponding to the major oligomers (based on molecular weight) are labeled according to their composition at the appropriate positions on the blot. MEF data are displayed on the far left to illustrate the distribution of p53 oligomers in cells lacking $\Delta 40$ p53. (B) p53 isoform expression in normal ESCs following p53 knockdown. p53 detection by PAb248 Western blot in normal ICR ESCs 6 or $48 \mathrm{~h}$ after treatment with p53-siRNA (right) or nontarget control siRNA (left). (C-E) p53 transcriptional activity in ESCs and EBs with varying doses of $\Delta 40$ p53. (C) p21, Nanog, IGF-1R, and Mdm2 gene expression in ICR and p44Tg ESCs (black bars) and EBs (gray bars). (D) p21, Nanog, IGF-1R, and Mdm2 gene expression in wild-type (WT 129/SvJ; black bars) and $\mathrm{p} 53^{+/ \Delta \mathrm{p} 44}(\Delta \mathrm{p} 44$; striped bars) ESCs. (E) p21 and Nanog mRNA expression in ICR ESCs, $48 \mathrm{~h}$ after transfection with nontarget control (CTL; black bars) or p53 (stippled bars) siRNA. ( F) ChIP analysis of p53 binding to the $p 21, N a n o g$, and IGF-1R promoters in ICR and p44Tg ESCs. Relative promoter occupancy by p53 in nontransgenic ICR (black bars) and $\mathrm{p} 44 \mathrm{Tg}$ (hatched bars) ESCs was determined by quantitative PCR, with IgG binding used for a negative control. $\left(^{\star}\right) P<0.05 ;\left(^{\star \star \star}\right) P<$ 0.001 (two-tailed Student's $t$-test).

$\mathrm{p} 53 / \Delta 40 \mathrm{p} 53$ heterotetramers relative to normal EBs. These findings suggest that $\Delta 40 \mathrm{p} 53$ might control the activity of p53 in the nucleus by sequestering active forms of the protein in the cytoplasm and preventing the interaction of p53 with target DNA sequences.

To determine if these changes in composition and localization of p53 oligomers had functional consequences, we compared the expression of several p53 target genes in $\mathrm{p} 53^{+/ \Delta \mathrm{p} 44}$ ESCs, $\mathrm{p} 44 \mathrm{Tg}$ ESCs, and EBs to the appropriate normal controls. We assessed the transactivation function of $\mathrm{p} 53$ via $\mathrm{p} 21$ and $\mathrm{Mdm} 2$ expression and measured p53 transsuppression function through the Nanog and IGF-1R genes. As shown in Figure 6, C and D, the differences were both transcript-specific and depended on whether the cells were grown under ESC or EB culture conditions. In ESCs, Nanog expression was significantly elevated in ESCs with excess $\triangle 40$ p53 (Fig. 6C, black bars) and significantly reduced in ESCs deficient in $\triangle 40$ p53 (Fig. 6D, striped bars). p21, on the other hand, was reduced in ESCs with excess $\Delta 40$ p53 (Fig. 6C, black bars) and elevated in ESCs deficient in $\triangle 40$ p53 (Fig. 6D, striped bars), although these differences did not reach statistical significance. In EBs, the only significant change in p44Tg cells was in the level of p21, which was reduced compared with normal (Fig. 6C, gray bars). We did observe the predicted increase in Nanog and reduction in IGF-1R in p44Tg EBs, but differences were not statistically significant. Mdm2 was not significantly differ- ent in cells with varying doses of $\Delta 40 \mathrm{p} 53$ (Fig. $6 \mathrm{C}, \mathrm{D}$ ). These findings demonstrate that the transcription factor function of p53 is altered in cells with varying levels of $\Delta 40 \mathrm{p} 53$, and that this effect is promoter-specific.

To determine if these effects of $\Delta 40 \mathrm{p} 53$ dose are mediated by full-length $\mathrm{p} 53$, we assayed the expression of $\mathrm{p} 21$ and Nanog in cells in which we experimentally reduced the amount of p53 relative to $\Delta 40 \mathrm{p} 53$. To do this, we took advantage of the fact that, although p53 and $\Delta 40 \mathrm{p} 53$ are both translated from the same mRNA, they have very different half-lives due to the presence or absence of the critical N-terminal Mdm2-binding site, which reduces the half-life of the protein from $9.5 \mathrm{~h}$ for $\Delta 40 \mathrm{p} 53$ to $\sim 0.5 \mathrm{~h}$ for full-length p53 (Rovinski et al. 1987). We used a p53 siRNA to inhibit the p53/A40p53 mRNA in normal ESCs and assessed target gene expression $48 \mathrm{~h}$ post-transfection, when the p53 protein was depleted by $\sim 90 \%$ but the level of $\Delta 40 \mathrm{p} 53$ protein remained high (Fig. 6B, note specific loss of p53 relative to $\Delta 40 \mathrm{p} 53$ in si-p53 transfected cells compared with control siRNA transfected cells). p21 expression was significantly reduced in p53 siRNA-treated cells (Fig. 6E, stippled bars), demonstrating that $\Delta 40 \mathrm{p} 53$ cannot sufficiently activate $\mathrm{p} 21$ expression in the absence of full-length p53. Nanog levels were also reduced in p53 siRNA-treated cells (Fig. 6E, stippled bars), indicating that full-length p53 is also required for $\Delta 40$ p53 to block transsuppression of the Nanog promoter, such as we observed in 
p44Tg ESCs (Fig. 6C, black bars). These findings demonstrate that the effects of $\Delta 40 \mathrm{p} 53$ on $\mathrm{p} 21$ gene activation and on Nanog gene suppression require full-length p53.

To elucidate the mechanism by which $\Delta 40 \mathrm{p} 53$ modulates the transcription factor function of full-length $\mathrm{p} 53$, we quantified p53 binding to the $p 21, N a n o g$, and $I g f-1 R$ promoters in normal and p44Tg ESCs using chromatin immunoprecipitation (ChIP) analysis. As depicted in Figure $6 \mathrm{~F}$, we found that a lower percentage of the Nanog, $p 21$, and Igf- $1 R$ promoters were bound by p53 in p44Tg ESCs, consistent with the reduced levels of p21 and increased levels of Nanog and IGF-1R found in these cells. These findings demonstrate that $\Delta 40 \mathrm{p} 53$ can block p53 from binding target promoters, and are consistent with a model in which an increased dose of $\Delta 40 \mathrm{p} 53$ results in altered expression of a select subset of p53-responsive genesincluding Nanog and Igf-1R - that are critical for making the switch from pluripotent ESCs to the more differentiated somatic cells.

\section{$\Delta 40 p 53$ controls the switch from pluripotency to differentiation via PI3K and IGF signaling}

We focused on the Igf- $1 R$ as one p53-responsive gene that might be critical for the ESC-to-somatic cell transition. As described in the previous section, IGF-1R mRNA expression was slightly elevated in $\mathrm{p} 44 \mathrm{Tg}$ EBs compared with ICR (Fig. 6C), and we determined that this result was likely caused by reduced binding of p53 to the Igf- $1 R$ promoter (Fig. 6F). We observed a significant decrease in the level of IGF-1R protein in normal ESCs following EB differentiation, but found that this decrease did not occur with EB differentiation of p44Tg ESCs (Fig. 7A). As the IGF-1R is known to play an important role in maintaining the pluripotent state of human ESCs (Bendall et al. 2007), we sought to determine if this increase in the level of the IGF-1R in p44Tg EBs might be responsible for their delayed differentiation. We compared the growth characteristics and expression of representative stem cell markers in cells grown under EB culture conditions in the presence or absence of a blocking antibody against the IGF-1R (IR3) or a pharmacological inhibitor of IGF signaling (LY294002, which inactivates PI3K). Both treatments completely reversed the accelerated growth of p44Tg EBs (Fig. 7B; Supplemental Fig. S2A). There was no significant additive effect on growth in EBs treated with both IR3 and LY294002, demonstrating that the accelerated growth of p44Tg EBs relative to ICR is mediated solely by increased activity of the IGF-1R. In contrast, we discovered that pluripotency in p44Tg EBs could be completely rescued by blocking PI3K, but only partially by blocking the IGF-1R. As shown in Figure 7, C and D, treatment of p44Tg EBs with IR3 caused a slight decrease in Nanog and Oct4 expression, while inhibition of PI3K with LY294002 (Fig. 7E,F) brought the levels of Nanog and Oct4 down to that found in normal EBs. At lower doses of LY294002, there was only partial rescue, and this was not improved by the addition of IR3 (Supplemental Fig. S2B,C). Together, these data indicate that $\Delta 40 \mathrm{p} 53$ controls the switch from ESC pluripotency to differentiation via the IGF-1R and PI3K signaling.
A
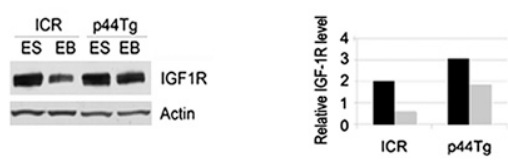

B

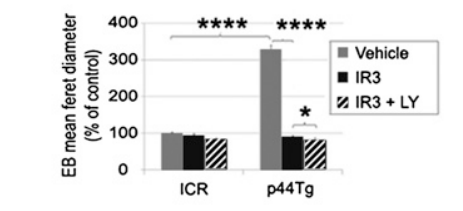

C
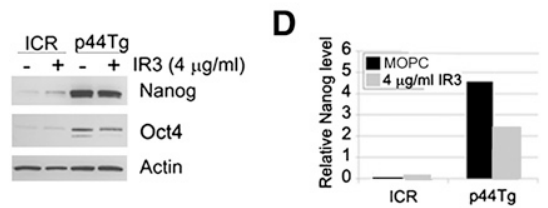

E

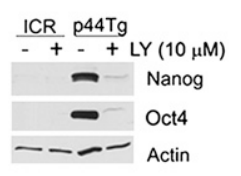

$\mathbf{F}$

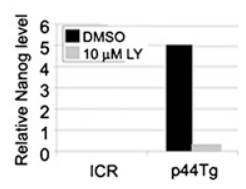

Figure 7. $\Delta 40 \mathrm{p} 53$ regulates ESC pluripotency via IGF/PI3K signaling. (A) IGF-1R expression in normal and p44Tg ESCs and EBs. Western blot (top) and protein quantitation (bottom). (Black bars) ESCs; (gray bars) EBs. Four independent samples for each genotype and cell type were analyzed. (B) Effect of blocking IGF/PI3K signaling on EB size. Data represent the mean diameters \pm SEM of ICR or p44Tg EBs after $5 \mathrm{~d}$ of treatment, and are expressed as percent of vehicle-treated ICR values. (Gray bars) vehicle-treated; (black bars) IR3-treated; (striped bars) IR3 LY294002-treated. Two to three sets of EB cultures were analyzed per treatment group, with each set consisting of 100-250 EBs. $\left.\left(^{\star}\right) P<0.05 ;{ }^{* \star \star \star *}\right) P<0.001$ (two-tailed Student's $t$-test). $(C-F)$ Effect of blocking IGF/PI3K signaling on expression of stem cell factors. Western blot analysis and quantitation of Nanog and Oct4 expression in EBs treated with the IGF-1Rblocking antibody IR3 $(C, D)$ or PI3K inhibitor LY294002 $(E, F)$. All values were normalized to actin. (Black bars) ESCs; (gray bars) EBs. See also Supplemental Figure S3.

\section{Discussion}

Previous studies have established that, although highly expressed, p53 is inactive in undifferentiated ESCs (Aladjem et al. 1998; Lin et al. 2005). Our results support the idea that p53 is maintained in an inactive state by the presence of $\Delta 40 \mathrm{p} 53$, one of its naturally occurring isoforms. We propose that $\Delta 40 \mathrm{p} 53$ is a critical regulator of p53 in ESCs, where it prevents the loss of pluripotency associated with p53 activation. Furthermore, we speculate that $\Delta 40 \mathrm{p} 53$ may play a similar role during early post-implantation stages of mammalian embryogenesis, which share with ESCs the unique characteristic of high $\Delta 40$ p53 expression. Like ESCs, early embryos express high levels of full-length p53 (Schmid et al. 1991; Lichnovsky et al. 1998), yet both embryos and ESCs lacking p53 are viable (Donehower et al. 1992; Sabapathy 
et al. 1997). Loss of the p53 inhibitor Mdm2, on the other hand, compromises ESC viability (McMasters et al. 1996) and causes early embryonic lethality (Jones et al. 1995). Viability is restored by codeletion of p53, demonstrating that negative regulation of p53 is essential during early embryogenesis and for the survival of ESCs. Similarly, loss of even a single dose of $\Delta 40 \mathrm{p} 53$ causes ESCs to lose pluripotency and compromises their ability to grow.

The mechanism by which $\Delta 40 \mathrm{p} 53$ regulates $\mathrm{p} 53$ is related to the structures of these two isoforms, which share most of the functional domains of the protein, including the tetramerization domain in the $\mathrm{C}$ terminus (for review, see Hollstein and Hainaut 2010). p53 and $\Delta 40$ p53 are known to form heterotetrameric complexes in several somatic cell lines (Courtois et al. 2002; Powell et al. 2008), and we showed by immunocytochemistry and subcellular fractionation that they colocalize and are likely to interact physically in ESCs as well. At the N terminus, however, these two proteins are substantially different. Translation of $\Delta 40 \mathrm{p} 53$ initiates at an alternative ribosome-binding site in exon 4 (Courtois et al. 2002), resulting in loss of the primary transactivation domain encoded in the first 40 amino acids, which severely impairs transcription factor capacity (Courtois et al. 2002). Multiple studies have shown that overexpression of $\Delta 40 \mathrm{p} 53$ in vitro reduces p53 activity by inhibiting its transactivation function (Zhu et al. 1998; Courtois et al. 2002) and promoting nuclear export of p53- $440 \mathrm{p} 53$ heterotetramers (Ghosh et al. 2004). In ESCs, elevated $\Delta 40 \mathrm{p} 53$ interferes with the ability of p53 to regulate the transcription of $p 21, N a n o g$, and Igf-1R, three genes that are known to be involved in the switch between pluripotent ESCs and differentiated somatic cells (Lin et al. 2005; Bendall et al. 2007; Hanna et al. 2009). This effect is attributable to direct interference with the binding of full-length p53 to its recognition sequences in the promoters of relevant target genes. In addition to these transcriptional effects, $\Delta 40 \mathrm{p} 53$ exerts control over the ability of ESCs (and presumably also of pluripotent cells of the early embryo) to grow by regulating signal transduction pathways-in particular, those that act through PI3K. One pathway known to be affected by $\Delta 40 \mathrm{p} 53$ is that of the IGF-1R. Our previous work clearly demonstrated that an increased dose of $\Delta 40 \mathrm{p} 53$ in mice results in higher than normal levels of the IGF-1R and constitutive upregulation of its associated signal transduction pathway in both embryonic and adult tissues and adult stem cells (Maier et al. 2004; Medrano et al. 2009). ESCs derived from these mice also display increased IGF-1R and increased activation of PI3K when grown under conditions favoring differentiation. Inhibition of IGF signaling by treatment with an IGF-1R-blocking antibody reversed the accelerated growth associated with increased $\Delta 40 \mathrm{p} 53$ expression, but caused only partial loss of Nanog and Oct4. Full suppression of these stem cell factors required inhibition of PI3K, indicating that additional upstream receptors are affected by $\Delta 40 \mathrm{p} 53$. One obvious candidate would be the LIF receptor, which is expressed in mouse ESCs (Ginis et al. 2004). The LIF receptor integrates signals from several critical kinases, including PI3K, to regulate expression of key pluripotency genes, including Nanog and Oct4 (Niwa et al. 2009). With the recent discovery that LIF is another p53 target gene (Hu et al. 2007), the possibility that changes in the dose of $\triangle 40 \mathrm{p} 53$ alter signaling downstream from the LIF receptor becomes highly likely, and something we are actively investigating.

Based on the findings described in this study, we propose that the principal function of $\Delta 40 \mathrm{p} 53$ in ESCs may be to suppress p53 activity and prevent transsuppression of factors such as Nanog and the IGF-1R that are important for maintaining the pluripotent and highly mitotic state of these cells. According to this model (Fig. 8), ESCs and their counterparts in normal embryogenesis (Fig. 8, left, yellow symbols) lose their ESC phenotype when $\Delta 40$ p53 levels decrease and the block on p53 activity is relieved. Another important consequence of decreased $\Delta 40 \mathrm{p} 53$ is a drop in the level of the IGF-1R, which occurs concomitant with the loss of pluripotency. Because IGF signaling acts through PI3K, an activator of Nanog expression (Niwa et al. 2009), a drop in the level of the receptor would result in reduced Nanog transactivation, which would reinforce the increase in Nanog transsuppression mediated by the now active p53. With loss of Nanog, cells become more restricted in potency and start to acquire the growth characteristics of somatic cells (Fig. 8, right, orange symbols). In addition to providing a mechanism for how p53 activity is regulated in ESCs, this model establishes an important distinction between the activity of p53 in embryonic cells, where its principal effect is due to target gene transsuppression, and p53 activity in maternal tissues (e.g., endometrium, indicated by the gray box in Fig. 8), where its main function appears to be the transactivation of genes that provide a supportive environment, such as LIF ( $\mathrm{Hu}$ et al. 2007; Paiva et al. 2009). One thing is very clear, however, and that is that the IGF axis plays a central role in controlling the
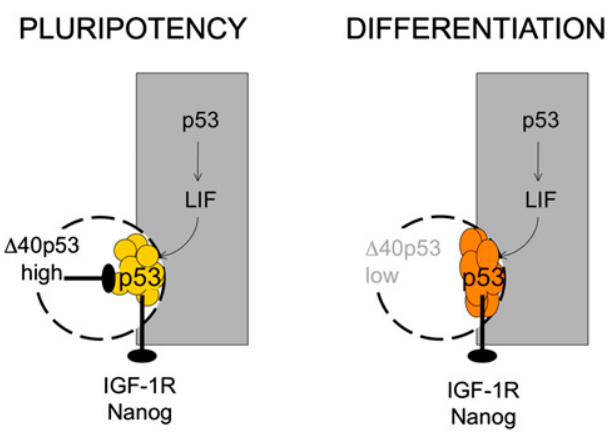

Figure 8. A model to explain how $\Delta 40 \mathrm{p} 53$ regulates the progression from pluripotency to differentiation in ESCs. In early embryos and ESCs (yellow symbols), $\Delta 40$ p53 expression is high. Pluripotency is maintained by blocking p53 transsuppression of critical factors, such as Nanog and the IGF-1R. One mechanism by which this could occur could be tetramerization of p53 with $\Delta 40 \mathrm{p} 53$ and sequestration in the cytoplasm. As $\Delta 40 \mathrm{p} 53$ expression in the embryo declines, p53 transsuppression can occur, causing extinction of Nanog and loss of pluripotency. Reduced signaling through the IGF-1R restricts proliferation to levels typical of somatic cells. In maternal tissues, shown here as a gray box, p53 transactivates LIF, a factor essential for implantation. 
pluripotency of mouse ESCs. Blocking the IGF-1R or downstream signaling through PI3K completely rescued the block to differentiation caused by excess $\Delta 40 \mathrm{p} 53$, including the adverse effects on p53-mediated transsuppression of Nanog. Thus, the IGF axis plays a central role in the switch between pluripotency and differentiation in mouse ESCs in much the same way as described previously for human ESCs (Bendall et al. 2007). $\Delta 40$ p53, by controlling the level of the IGF-1R, acts as a master regulator of this switch.

Previous work from our laboratory has demonstrated a role for $\Delta 40 \mathrm{p} 53$ in somatic cells, where an extra dose of p53 coding exclusively for this isoform results in reduced life span (Maier et al. 2004) and impaired regenerative capacity of adult stem cells (Medrano et al. 2009). In embryonic cells, on the other hand, $\Delta 40$ p53 enhances survival and promotes a highly proliferative state that perpetuates regenerative capacity. These seemingly contradictory adult and embryonic phenotypes can be explained as resulting from disparate regulation of proliferation and cell cycle progression in these two cells types. Adult stem cell self-renewal is controlled by cyclindependent kinase inhibitors such as p21, p27, and p16, which are absent from ESCs (White and Dalton 2005; Tarasov et al. 2008), at least in part because p53 is needed to transactivate their expression. The differences in cell cycle regulation between ESCs and somatic cells can also explain why we do not see cell cycle defects in ESCs with excess $\Delta 40 p 53$. In cells deficient in $\Delta 40 p 53$, on the other hand, cell cycle progression is profoundly affected, with the cells acquiring the cell cycle profile of a typical somatic cell precociously when they lose pluripotency. In fact, the unique cell cycle of ESCs has been shown to be inherently linked to pluripotency (White and Dalton 2005). In summary, the data described here provide valuable insight into the contributions of p53 and $\Delta 40$ p53 to the maintenance of ESC pluripotency. We identified $\Delta 40 \mathrm{p} 53$ as the p53 isoform expressed highly and specifically in human and mouse ESCs and in early post-implantation mouse embryos. We showed that, by modulating $\Delta 40 \mathrm{p} 53$ expression, we can selectively alter $\mathrm{p} 53$ activation in a manner that supports pluripotency. Such precise regulation of p53 function could provide a safer method for the suppression of p53 during somatic cell reprogramming.

\section{Materials and methods}

\section{Mouse ESC culture and differentiation}

Wild-type 129/SvJ ESCs were a gift of Dr. Scott Zeitlin, and wildtype ICR ESCs were a gift from Dr. Robin Wesselschmidt. p44Tg ESCs were isolated from blastocyst-stage embryos using established methods. ESCs were maintained on mitotically inactivated STO fibroblasts in DMEM supplemented with 15\% fetal bovine serum (FBS), nonessential amino acids, $\beta$-mercaptoethanol, l-glutamine, nucleosides, and $1000 \mathrm{U} / \mathrm{mL}$ LIF (all from Chemicon). Medium was replaced daily and cells were passaged every 2-3 d by trypsination. ESCs were differentiated to form EBs using a multiwell plate format protocol (Ezekiel et al. 2007), or into neural stem cell precursors using a serum-free adherent monoculture system (Conti et al. 2005).
Generation of ESCs with reduced $\Delta 40 p 53$

The $\Delta \mathrm{p} 44$ targeting construct was generated from a 6-kb genomic fragment of $p 53$ (introns 1-6) as follows: The translation start site for $\Delta 40 \mathrm{p} 53$ (M41) was converted to an alanine using site-directed PCR mutagenesis (Ex-Site kit; Stratagene), and a floxed pA-STOP cassette conferring G418 resistance was inserted into the Xbal site in exon 4. Wild-type 129/SvJ ESCs were electroporated with the linearized $\Delta \mathrm{p} 44$ targeting construct and cultured under G418 selection for 2 wk. Heterozygous p53 ${ }^{\Delta \mathrm{p} 44-\mathrm{STOP}}$ ESC lines were identified by Southern blot. To eliminate the selection cassette, p53 $3^{+/ \Delta \mathrm{p} 44-\mathrm{STOP}}$ ESCs were electroporated with a Cre recombinase plasmid and plated under clonal conditions. Replica cultures were established for each clone to identify G418-sensitive $\mathrm{p} 53^{\Delta \mathrm{p} 44}$ ESC lines, and recombination was confirmed by PCR.

\section{Pharmalogical inhibition of IGF/PI3K signaling}

IGF-1R activity was inhibited using the IGF-1R $\alpha$-subunit-blocking antibody IR3 (Calbiochem/EMD Chemicals), and PI3K activity was inhibited using LY294002 (Cell Signaling). MOPC-21 (Sigma) was used as an isotype control for IR3, and DMSO (Sigma) was used as the vehicle control for LY294002. EBs were treated with the specified inhibitors for $4 \mathrm{~d}$. IR3 was used at concentrations ranging from 1 to $4 \mu \mathrm{g} / \mathrm{mL}$ and LY294002 was used at 5-10 $\mu \mathrm{M}$. EB diameters were measured using NIH ImageJ software.

\section{SiRNA transfection}

ESCs $\left(10^{6}\right)$ were seeded in six-well plates $1 \mathrm{~d}$ before transfection. Cells were transfected with $100 \mathrm{nM}$ ON-TARGET plus SMARTpool siRNA (p53, L-040642, or nontarget, D-001810; Dharmacon) using DharmaFECT1 (Dharmacon) and harvested 6 or 48 h later.

\section{Proliferation assays}

To generate growth curves for ESCs, we seeded $4 \times 10^{4}$ cells per well onto gelatin-coated 24 -well plates. Triplicate wells were dissociated and counted by hemocytometer each day thereafter for $7 \mathrm{~d}$, and cell medium was replaced daily.

\section{Flow cytometry}

Single-cell suspensions were fixed with ethanol, stained with SSEA-1 primary antibodies (University of Iowa, Hybridoma Bank) and fluorescently conjugated secondary antibodies (BD Biosciences), then analyzed by flow cytometry. Cell cycle studies were performed by FACS analysis using the far-red fluorescent DNA dye DRAQ5. For apoptosis studies, ESCs were treated with $10 \mu \mathrm{g} / \mathrm{mL}$ etoposide for $12 \mathrm{~h}$ to induce DNA damage, then stained with Annexin V. At least 10,000 events per sample were acquired using a FACScalibur flow cytometer (BD Biosciences), and analyzed using FloJo or ModFitLT version 3.1 software.

\section{Western blot analysis}

Total protein was isolated as described (Sasaki et al. 2006) and analyzed according to standard Western blotting procedures. Antibody sources include p53 monoclonal PAb248 (gift of Ettore Appella), PAb421 and PAb1801 (Calbiochem/EMD Chemicals), D0-1 (Santa Cruz Biotechnology), p53 polyclonal CM5 (Vector Laboratories), IGF-1R (Santa Cruz Biotechnology), Nanog (Bethyl Laboratories), Oct4 (Santa Cruz Biotechnology), Actin (MP Biomedicals,), and GAPDH (Ambion). 
Ungewitter and Scrable

\section{Subcellular fractionation}

Nuclear and cytosolic protein fractions were prepared as described previously (Kornberg et al. 1989).

p53 oligomer analysis

p53 and $\Delta 40$ p53 homo-oligomer and hetero-oligomer complexes were measured using a technique described by Powell et al. (2008). Samples were then subjected to Western blot analysis using the p53 antibody PAb248.

\section{Real-time PCR analysis}

Total RNA was isolated from ESCs using an RNeasy kit (Qiagen) and reversed-transcribed using an RNA to cDNA kit (Applied Biosystems). Real-time PCR was performed on an ABI 7900HT machine with TaqMan PCR Master Mix (Applied Biosystems). PCR conditions consisted of a 2 -min UNG activation at $50^{\circ} \mathrm{C}$ and a 10 -min hot start at $95^{\circ} \mathrm{C}$, followed by 40 cycles of $15 \mathrm{sec}$ at $95^{\circ} \mathrm{C}$ and $1 \mathrm{~min}$ at $60^{\circ} \mathrm{C}$. The average threshold cycle $(\mathrm{Ct})$ for each gene was determined from triplicate reactions, and the levels of gene expression relative to GAPDH were calculated using RQ Manager software (Applied Biosystems). Gene expression assays for p53 (Mm01731287), p21 (Mm01303209), Mdm2 (Mm01233136), Nanog (Mm02019550), IGF-1R (Mm00802831), and GAPDH (Mm99999915) were obtained from Applied Biosystems.

\section{ChIP assay}

ChIP analysis of in vivo binding of p53 to target promoters was performed as described (Nelson et al. 2006). Briefly, cells were fixed with $1.42 \%$ formaldehyde for $15 \mathrm{~min}$ at room temperature, then neutralized with $125 \mathrm{mM}$ glycine for $5 \mathrm{~min}$. Cells were lysed with $1 \mathrm{~mL}$ of immunoprecipitation buffer $(150 \mathrm{mM} \mathrm{NaCl}$, $50 \mathrm{mM}$ Tris- $\mathrm{HCl}$ at $\mathrm{pH} 7.5,5 \mathrm{mM}$ EDTA, $0.5 \%$ NP-40, $1.0 \%$ Triton X-100) and sonicated to an average fragment size of $1.0 \mathrm{~kb}$ using an ultrasonic water bath. One-hundred microliters of each chromatin sample was incubated for $12 \mathrm{~h}$ at $4^{\circ} \mathrm{C}$ with $5 \mu \mathrm{g}$ of antibodies against p53 (PAb421; Santa Cruz Biotechnology), acetylated H3 (Millipore), or IgG (mock, Vector Laboratories). Immune complexes were collected with protein A/G-agarose beads and DNA was collected using a Chelex 100 slurry (BioRad), then treated with Proteinase K. The amounts of DNA in the immunoprecipitates and the input were quantified by realtime PCR using the same machine, buffers, and cycling conditions described previously. Relative occupancy was estimated using the equation: $2^{\mathrm{Ct}^{\text {mock }}-\mathrm{Ct}^{\text {specific }}}$, where $\mathrm{Ct}^{\text {mock }}$ and $\mathrm{Ct}^{\text {specific }}$ are mean threshold cycles of triplicate PCR samples. The primer sequences for $\mathrm{p} 21$ and IGF-1R are as follows: p21, 5'-TGTCCT CGCCCTCATCTATT $-3^{\prime}$ and $5^{\prime}$-GCCTATGTTGGGAAACAA GA - $3^{\prime}$; IGF-1R, 5' -ATGACTTGGGCTGGTAGTGG - $3^{\prime}$ and $5^{\prime}$-AA GCTGGCCTAAACCAGACA -3'; an inventoried gene expression assay was used for Nanog promoter detection (Mm02019550, Applied Biosystems).

\section{Immunocytochemistry}

ESCs were plated onto a layer of mitotically inactivated STO fibroblasts on glass coverslips and cultured overnight. Cells were fixed with $4 \%$ paraformaldehyde for $10 \mathrm{~min}$, permeabilized with $0.1 \%$ Triton X-100 for $10 \mathrm{~min}$, then blocked in a solution of $10 \%$ normal goat serum and $0.1 \%$ Triton X-100 in PBS for $30 \mathrm{~min}$, and incubated with primary antibodies (described previously) diluted in blocking solution overnight at $4^{\circ} \mathrm{C}$. The following day, cells were reacted with fluorescently conjugated secondary antibodies
(Invitrogen) for $1 \mathrm{~h}$ at $4^{\circ} \mathrm{C}$. Nuclei were counterstained using $10 \mu \mathrm{M}$ DRAQ5 (Biostatus Ltd.), and coverslips were mounted using Fluoromount. Microscopy was performed using a Zeiss Std 510 confocal microscope, and images were processed using Zeiss LSM Image Browser software.

\section{AP staining}

ESCs were cultured for a minimum of $5 \mathrm{~d}$ on a layer of mitotically inactivated STO fibroblasts prior to AP staining. Cells were fixed with gluteraldehyde and stained with a solution of $4 \%$ Napthol AS-MX phosphate (Sigma) and 1\% Fast Red TR for $15 \mathrm{~min}$ at room temperature.

\section{Acknowledgments}

We thank Wendy Baker for excellent technical assistance. We are grateful to Dr. Scott Zeitlin (University of Virginia, Charlottesville, VA) for ESCs, the Neo-STOP construct, and helpful discussions; Mike Solga and Joann Lannigan at University of Virgina flow cytometry facility for assistance with cell cycle analysis and apoptosis studies; Dr. Benjamin Madden at the Mayo Clinic protein core facility for mass spectrometry services; Dr. Robin Wesselschmidt (Primogenix, Inc., Los Angeles, CA) for ICR ESCs; Dr. Raj Rao (Virginia Commonwealth University, Richmond, VA) for human ESC lysates; Dr. Zheng Fu (University of Virginia) for helpful discussions; Dr. Ettore Appella (National Cancer Institute, Bethesda, MD) for PAb248 p53 antibody; and Dr. Tyler Jacks (Massachusetts Institute of Technology, Cambridge, MA) for the genomic p53 fragment used in the targeting construct. Dr. Olga Sarmento provided the expertise necessary for us to carry out the ChIP assays, as well as a context for understanding how events in ESCs could reflect events occurring during early mammalian embryogenesis. This work was supported by National Research Service Award F31NS061405 predoctoral fellowship to E.U., and PHS award R01AG026094 and Senior Scholar in Aging award from the Ellison Medical Research Foundation to H.S.

\section{References}

Aladjem MI, Spike BT, Rodewald LW, Hope TJ, Klemm M, Jaenisch R, Wahl GM. 1998. ES cells do not activate p53dependent stress responses and undergo p53-independent apoptosis in response to DNA damage. Curr Biol 8: 145-155.

Bendall SC, Stewart MH, Menendez P, George D, Vijayaragavan K, Werbowetski-Ogilvie T, Ramos-Mejia V, Rouleau A, Yang J, Bosse M, et al. 2007. IGF and FGF cooperatively establish the regulatory stem cell niche of pluripotent human cells in vitro. Nature 448: 1015-1021.

Bourdon JC, Fernandes K, Murray-Zmijewski F, Liu G, Diot A, Xirodimas DP, Saville MK, Lane DP. 2005. p53 isoforms can regulate p53 transcriptional activity. Genes Dev 19: 21222137.

Conti L, Pollard SM, Gorba T, Reitano E, Toselli M, Biella G, Sun Y, Sanzone S, Ying QL, Cattaneo E, et al. 2005. Nicheindependent symmetrical self-renewal of a mammalian tissue stem cell. PLoS Biol 3: e283. doi: 10.1371/journal.pbio. 0030283.

Corbet SW, Clarke AR, Gledhill S, Wyllie AH. 1999. P53dependent and -independent links between DNA-damage, apoptosis and mutation frequency in ES cells. Oncogene 18: 1537-1544.

Courtois S, Verhaegh G, North S, Luciani MG, Lassus P, Hibner U, Oren M, Hainaut P. 2002. $\Delta$ N-p53, a natural isoform of 
p53 lacking the first transactivation domain, counteracts growth suppression by wild-type p53. Oncogene 21: 6722-6728. Donehower LA, Harvey M, Slagle BL, McArthur MJ, Montgomery CA Jr, Butel JS, Bradley A. 1992. Mice deficient for p53 are developmentally normal but susceptible to spontaneous tumours. Nature 356: 215-221.

Ezekiel UR, Muthuchamy M, Ryerse JS, Heuertz RM. 2007. Single embryoid body formation in a multi-well plate. Electron J Biotechnol 10: 328-335.

Ghosh A, Stewart D, Matlashewski G. 2004. Regulation of human p53 activity and cell localization by alternative splicing. Mol Cell Biol 24: 7987-7997.

Ginis I, Luo Y, Miura T, Thies S, Brandenberger R, Gerecht-Nir S, Amit M, Hoke A, Carpenter MK, Itskovitz-Eldor J, et al. 2004. Differences between human and mouse embryonic stem cells. Dev Biol 269: 360-380.

Hanna J, Saha K, Pando B, van Zon J, Lengner CJ, Creyghton MP, van Oudenaarden A, Jaenisch R. 2009. Direct cell reprogramming is a stochastic process amenable to acceleration. Nature 462: 595-601.

Hollstein M, Hainaut P. 2010. Massively regulated genes: The example of TP53. J Pathol 220: 164-173.

Hong H, Takahashi K, Ichisaka T, Aoi T, Kanagawa O, Nakagawa M, Okita K, Yamanaka S. 2009. Suppression of induced pluripotent stem cell generation by the p53-p21 pathway. Nature 460: 1132-1135.

Hu W, Feng Z, Teresky AK, Levine AJ. 2007. p53 regulates maternal reproduction through LIF. Nature 450: 721-724.

Jones SN, Roe AE, Donehower LA, Bradley A. 1995. Rescue of embryonic lethality in $\mathrm{Mdm} 2$-deficient mice by absence of p53. Nature 378: 206-208.

Kawamura T, Suzuki J, Wang YV, Menendez S, Morera LB, Raya A, Wahl GM, Belmonte JC. 2009. Linking the p53 tumour suppressor pathway to somatic cell reprogramming. Nature 460: 1140-1144.

Kornberg RD, LaPointe JW, Lorch Y. 1989. Preparation of nucleosomes and chromatin. Methods Enzymol 170: 3-14.

Lane DP, Stephen CW, Midgley CA, Sparks A, Hupp TR, Daniels DA, Greaves R, Reid A, Vojtesek B, Picksley SM. 1996. Epitope analysis of the murine p53 tumour suppressor protein. Oncogene 12: 2461-2466.

Li H, Collado M, Villasante A, Strati K, Ortega S, Canamero M, Blasco MA, Serrano M. 2009. The Ink4/Arf locus is a barrier for iPS cell reprogramming. Nature 460: 1136-1139.

Lichnovsky V, Kolar Z, Murray P, Hlobilkova A, Cernochova D, Pospisilova E, Vojtesek B, Nenutil R. 1998. Differences in p53 and $\mathrm{Bcl}-2$ expression in relation to cell proliferation during the development of human embryos. Mol Pathol 51: 131-137.

Lin T, Chao C, Saito S, Mazur SJ, Murphy ME, Appella E, Xu Y. 2005. p53 induces differentiation of mouse embryonic stem cells by suppressing Nanog expression. Nat Cell Biol 7: 165171.

Maier B, Gluba W, Bernier B, Turner T, Mohammad K, Guise T, Sutherland A, Thorner M, Scrable H. 2004. Modulation of mammalian life span by the short isoform of p53. Genes Dev 18: $306-319$.

Maimets T, Neganova I, Armstrong L, Lako M. 2008. Activation of p53 by nutlin leads to rapid differentiation of human embryonic stem cells. Oncogene 27: 5277-5287.

Marion RM, Strati K, Li H, Murga M, Blanco R, Ortega S, Fernandez-Capetillo O, Serrano M, Blasco MA. 2009. A p53-mediated DNA damage response limits reprogramming to ensure iPS cell genomic integrity. Nature 460: 1149-1153.

McMasters KM, Montes de Oca Luna R, Pena JR, Lozano G. 1996. mdm2 deletion does not alter growth characteristics of p53-deficient embryo fibroblasts. Oncogene 13: 1731-1736.
Medrano S, Burns-Cusato M, Atienza MB, Rahimi D, Scrable H. 2009. Regenerative capacity of neural precursors in the adult mammalian brain is under the control of p53. Neurobiol Aging 30: 483-497.

Nagy A, Gertsenstein M, Vintersten K, Behringer R. 2003. Manipulating the mouse embryo: A laboratory manual, 3rd ed. Cold Spring Harbor Laboratory Press, Cold Spring Harbor, NY.

Nelson JD, Denisenko O, Bomsztyk K. 2006. Protocol for the fast chromatin immunoprecipitation (ChIP) method. Nat Protoc 1: 179-185.

Niwa H, Ogawa K, Shimosato D, Adachi K. 2009. A parallel circuit of LIF signalling pathways maintains pluripotency of mouse ES cells. Nature 460: 118-122.

Paiva P, Menkhorst E, Salamonsen L, Dimitriadis E. 2009. Leukemia inhibitory factor and interleukin-11: Critical regulators in the establishment of pregnancy. Cytokine Growth Factor Rev 20: 319-328.

Powell DJ, Hrstka R, Candeias M, Bourougaa K, Vojtesek B, Fahraeus R. 2008. Stress-dependent changes in the properties of $\mathrm{p} 53$ complexes by the alternative translation product $\mathrm{p} 53 /$ 47. Cell Cycle 7: 950-959.

Rovinski B, Munroe D, Peacock J, Mowat M, Bernstein A, Benchimol S. 1987. Deletion of $5^{\prime}$-coding sequences of the cellular p53 gene in mouse erythroleukemia: A novel mechanism of oncogene regulation. Mol Cell Biol 7: 847-853.

Sabapathy K, Klemm M, Jaenisch R, Wagner EF. 1997. Regulation of ES cell differentiation by functional and conformational modulation of p53. EMBO I 16: 6217-6229.

Sasaki T, Maier B, Bartke A, Scrable H. 2006. Progressive loss of SIRT1 with cell cycle withdrawal. Aging Cell 5: 413-422.

Schmid P, Lorenz A, Hameister H, Montenarh M. 1991. Expression of p53 during mouse embryogenesis. Development 113: 857-865.

Stephen CW, Helminen P, Lane DP. 1995. Characterisation of epitopes on human p53 using phage-displayed peptide libraries: Insights into antibody-peptide interactions. I Mol Biol 248: $58-78$.

Suzuki O, Matsuda J, Takano K, Yamamoto Y, Asano T, Naiki M, Kusanagi M. 1999. Effect of genetic background on establishment of mouse embryonic stem cells. Exp Anim 48: 213-216.

Tarasov KV, Tarasova YS, Tam WL, Riordon DR, Elliott ST, Kania G, Li J, Yamanaka S, Crider DG, Testa G, et al. 2008. B-MYB is essential for normal cell cycle progression and chromosomal stability of embryonic stem cells. PLOS ONE 3: e2478. doi: 10.1371/journal.pone.0002478.

Utikal J, Polo JM, Stadtfeld M, Maherali N, Kulalert W, Walsh RM, Khalil A, Rheinwald JG, Hochedlinger K. 2009. Immortalization eliminates a roadblock during cellular reprogramming into iPS cells. Nature 460: 1145-1148.

Wang J, Feng XH, Schwartz RJ. 2004. SUMO-1 modification activated GATA4-dependent cardiogenic gene activity. I Biol Chem 279: 49091-49098.

Warnock LJ, Raines SA, Mee TR, Milner J. 2005. Role of phosphorylation in p53 acetylation and PAb421 epitope recognition in baculoviral and mammalian expressed proteins. FEBS J 272: 1669-1675.

White J, Dalton S. 2005. Cell cycle control of embryonic stem cells. Stem Cell Rev 1: 131-138.

Yewdell JW, Gannon JV, Lane DP. 1986. Monoclonal antibody analysis of p53 expression in normal and transformed cells. J Virol 59: 444-452.

Zhu J, Zhou W, Jiang J, Chen X. 1998. Identification of a novel p53 functional domain that is necessary for mediating apoptosis. J Biol Chem 273: 13030-13036. 


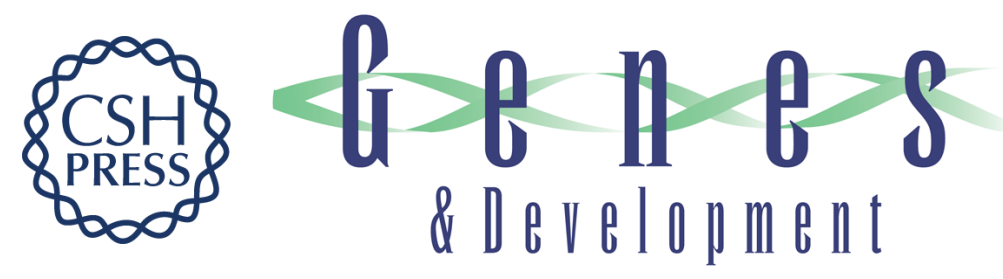

\section{$\Delta 40$ p53 controls the switch from pluripotency to differentiation by regulating IGF signaling in ESCs}

Erica Ungewitter and Heidi Scrable

Genes Dev. 2010, 24:

Access the most recent version at doi:10.1101/gad.1987810

Supplemental http://genesdev.cshlp.org/content/suppl/2010/10/21/24.21.2408.DC1
Material

References This article cites 43 articles, 10 of which can be accessed free at:

http://genesdev.cshlp.org/content/24/21/2408.full.html\#ref-list-1

License

Email Alerting Receive free email alerts when new articles cite this article - sign up in the box at the top

Service right corner of the article or click here.

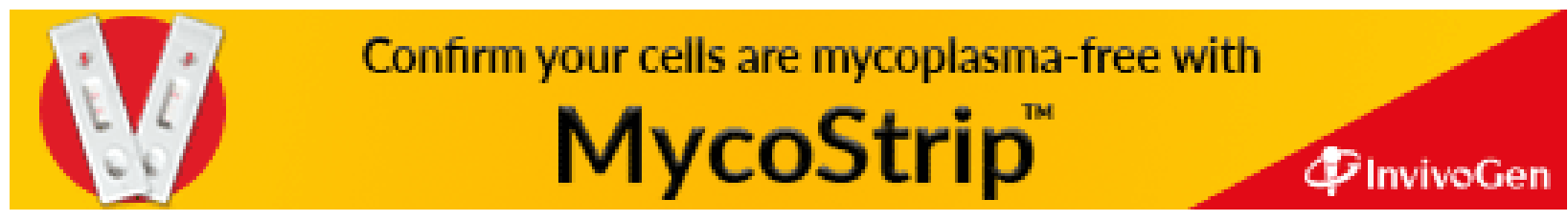

